\title{
Modeling of Students' Competency Development in the Higher Education Distant Learning System
}

\author{
Karmanova Ekaterina Vladimirovna \\ Power Engineering and Automated Systems Institute \\ NMSTU \\ Magnitogorsk, Russia \\ Monitor81@mail.ru \\ Efimova Irina Yuryevna \\ Power Engineering and Automated Systems Institute \\ NMSTU \\ Magnitogorsk, Russia \\ iefimova@list.ru \\ Guseva Elena Nikolaevna \\ Power Engineering and Automated Systems Institute \\ NMSTU \\ Magnitogorsk, Russia \\ kellymy7@rambler.ru
}

\begin{abstract}
The article considers a problem of monitoring of the well-formedness degree of students' competencies in the system of distant learning technologies. In particular, the article indicates the lack of commonly-accepted technologies of students' competency assessment. The authors demonstrate an activity model as well as functional and conceptual models (to-be) of the students' competency development through a study of the current distant learning system of Nosov Magnitogorsk State Technical University. Not only do the models developed make it possible to depict an organisational and technical aspect of the students' competency development in the distant learning system but support creation of a programming solution ensuring an automated monitoring of the well-formedness degree of students' competencies.

Keywords: competence-based approach, monitoring of competencies, distant learning system, higher education institution, activity model, conceptual model, functional model, unified modeling language, object-oriented approach.
\end{abstract}

\section{INTRODUCTION}

A competence-based approach becomes a modern approach which serves to solve a problem of the education quality improvement. According to the approach, academic activities should be designed to achieve educational results which will manifest themselves in well-formed students' competencies. The concept of a competency should be interpreted in an integrated manner as a structure composed of different

\author{
Kostina Natalia Nikolaevna \\ History, Philology and Foreign Languages Institute \\ NMSTU \\ Magnitogorsk, Russia \\ agatik01@mail.ru
}

Savelyeva Lyudmila Alexandrovna

Power Engineering and Automated Systems InstituteNMSTU

Magnitogorsk, Russia sla4@mail.ru

Bobrova Inna Igorevna

Power Engineering and Automated Systems Institute NMSTU

Magnitogorsk, Russia

friend bi@mail.ru

parts. In a general way, a competency is understood as a combination of knowledge, skills, and experience, personal qualities, and abilities in the system of education [1]. Accordingly, the new Federal State Standards of Higher Professional Education (FSSHPE) are designed on the basis of a competence-based approach where common cultural and professional competencies are emphasized as mandatory requirements to the results of academic activities and graduate students' competencies [2]. The necessity in development of measures to assess graduate students' competencies is specified in the Standards requirements as well as in a number of other regulatory documents. For example, a mechanism of an integrated assessment of student's competencies requires development for all levels of the education system according to the concept of the Federal Targeted Programme on the development of Russian education for 2011-2015 [3].

The Law of the Russian Federation on Education [4] distinguishes several modes of university study (intramural, extramural, evening classes). Each mode of study has special features enabling to organize academic activities for students tailored to their needs, a student's life style, in particular, when he/she studies alongside employment. In this case, an extramural delivery of distant learning appears to be a more suitable mode of study. There is a developed informational-educational environment at modern Russian universities [5]. Distant learning systems (hereinafter - DLS) are created as part 
of this environment. However, what is still lacking is a commonly-accepted technology of monitoring the development of a certain students' competency trained within the DLS in spite of the fact that distant learning technologies are widely spread among many universities. In addition, the existing competency assessment methodologies are unmanageable. They do not take account of specifics of the competency development in the framework of the DLS. A number of scientists consider that this problem affects an intramural mode of study as well $[6,7]$.

The research goal is to describe a model of the development of students' competencies trained within the DLS of a university, which will make it possible to implement an automated independent monitoring of a competence-oriented training later on. The research considers an organisational and technical aspect of the students' competency development, which, in turn, includes description of a general organisational structure of the DLS as well as devices, techniques, and means used to organize academic activities in the DLS of the university which enhance a high-quality development of students' competencies taking distance-learning courses.

\section{MATERIALS AND METHODS}

An adequate choice of a methodology is one of the main conditions of business process modeling. An object-oriented paradigm was used as a key methodology of the subject field modeling, which made it possible to avoid sophisticated models. In addition, the Unified Modeling Language (UML) was chosen a key model presentation tool. The UML (Unified Modeling Language) is a graphic modeling language of general purpose designed to specify, visualize, design and document all the artifacts created when developing programming systems [8]. The UML was chosen due to the following properties: models (they are diagrams in the notation of the language) enable to depict the subject field under consideration and to give an easy-tounderstand description of the process to a new user. Moreover, the UML will make it possible to proceed from the models of the subject field to the development of a programming solution as far as the competency development within the DLS is described.

The current DLS of the Nosov Magnitogorsk State Technical University was chosen for a visual modeling of the development of students' competencies. The DLS of the NMSTU exemplifies business processes typical of an organisational and technical aspect of practicing a competence-based approach. Besides, it is the right thing to say about creation of TO-BE models rather than ASIS models. TO-BE models show how a competenceoriented training will be practiced with consideration of the specifics of the current DLS of the University. It should be pointed out that the DLS of the NMSTU has been under operation since 2011. It is deployed on
Moodle [9] and integrated with the current Student information system of the University.

\section{RESULTS}

The analysis of the DLS of the University has shown the following: the system is represented as a combination of electronic courses on different disciplines; each course consists of several modules; a module includes a theoretical content, a practical activity, and a selfassessment test; a final test on a discipline under study terminates an electronic course; a score log is available for each electronic course which displays test scores, practical activity scores, and a current course score. However, there is no information about what modules develop competencies under the curriculum, what tests and practical activities enable assessment of the wellformedness degree of any given students' competency. Consequently, the DLS does not exercise monitoring of the well-formedness degree of students' competencies being one of the requirements of a competence-based approach.

\section{A. Activity model}

A UML activity diagram was used to model business processes of the students' competency development. The diagram makes it possible to render the logic or the activity-change sequence. At the same time, the result of an activity is emphasized. In general, the diagram describes the algorithm of the process under consideration. The activity diagram is represented as an activity graph with action or activity states being its nodes, and action state changes being its arcs. In addition, vertical lines are used to demarcate regions containing model components the responsibility for the performance of which belongs to certain actors.

The competency development process has been divided into following steps:

- a preparatory step;

- a training step;

- $\quad$ an analysis step (Fig 1).

Let's describe each step as a separate activity diagram.

Development of a required academic content for the DLS is the main objective of the preparatory step, which includes development of electronic courses containing information about competencies to be developed and tools of their diagnostics and assessment as well as a theoretical content, exercises, and tests. The University serves as the input data. The output looks as follows:

- a competency matrix;

- a competency passport;

- a curriculum;

- a global group of competencies in the educational programme;

- different electronic courses corresponding to disciplines of the educational programme.

Key participants are: 
- members of the academic methodological association (AMA) of a department, a school, or an institute;

- faculty of departments;

- original authors of electronic courses;

- the DLS administrator.
Fig. 2 shows an activity diagram for a preparatory step. We might note that the process initiation is identified with a black circle, and a black enclosed circle indicates the process termination.

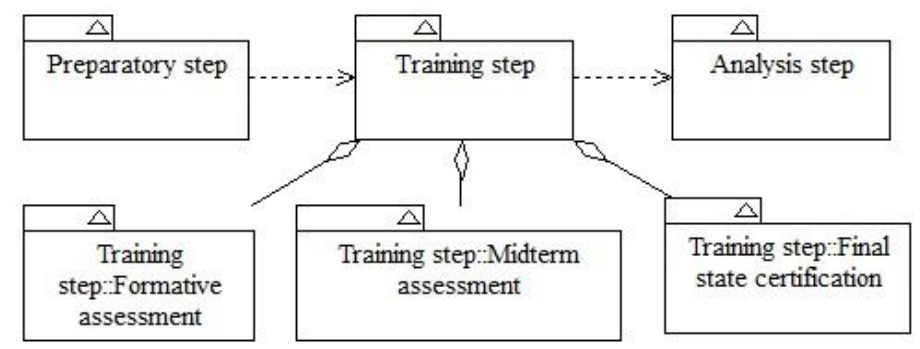

Fig. 1 - Three steps of the students' competency development process

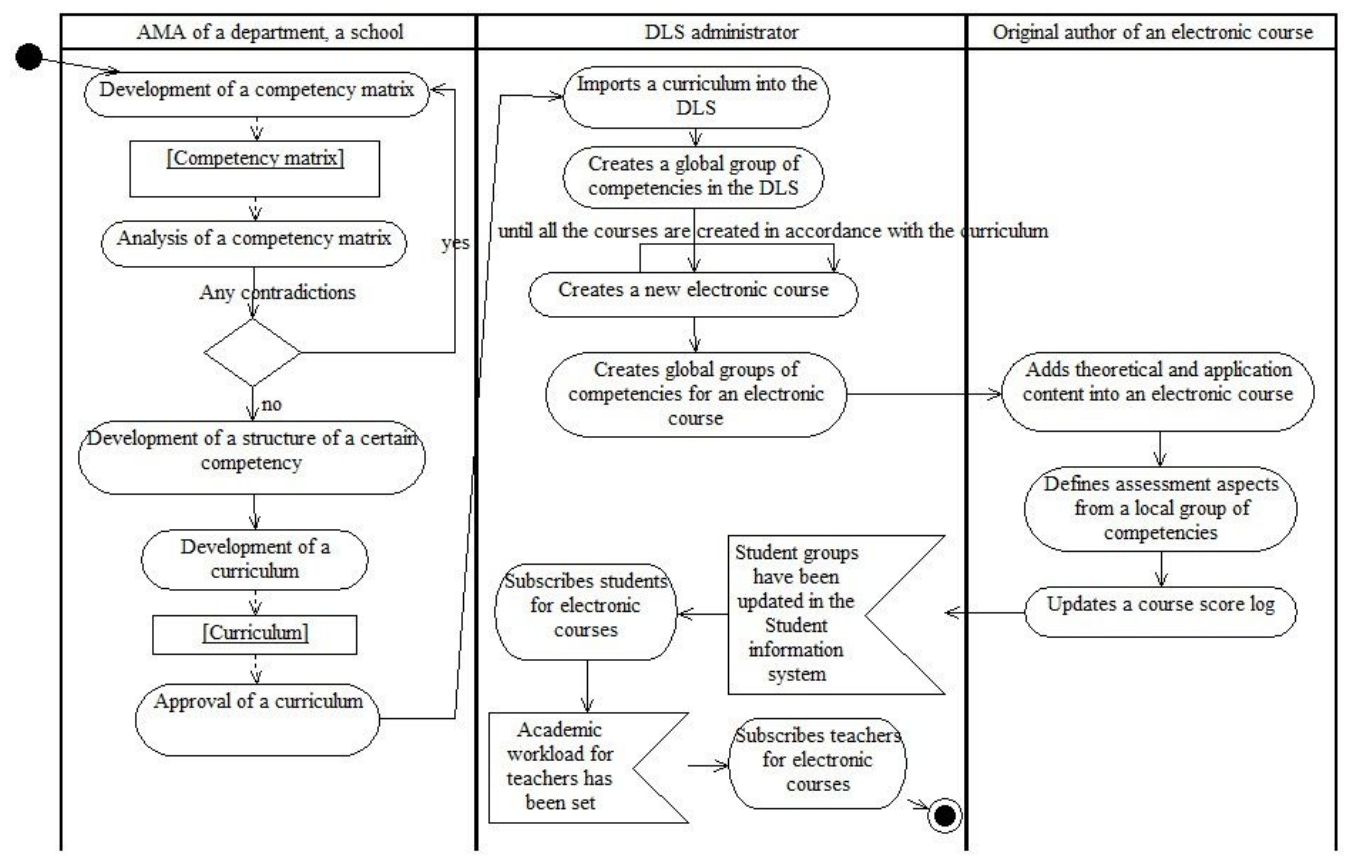

Fig. 2 - Activity diagram of the preparatory step

Let's consider core activities sectioned out on the diagram and indicate actors responsible for them. First, the members of the academic methodological association develop a competency matrix, passports for each competency, and a curriculum on a corresponding programme track. Then, with a relevant global group of competencies being created for each educational programme on the DLS level, the DLS administrator imports curricula into the system. After that, electronic courses are created according to curriculum disciplines. A local group of competencies (a list of competencies developed on the discipline level) is created in an electronic course respectively.
The original authors supply electronic courses with the content provided by teachers of the disciplines. Basing on a competency assessment methodology provided by the teachers, the authors also assign a list of competencies to be assessed from a local group of competencies for each diagnostic material and update a course score log by setting "weights" (a degree of complexity) for a particular diagnostic material. We might note that an electronic course score log stores not only the data on the "weights" and diagnostics materials but the data on tests progress and exercise scores given by the teachers. 
The DLS administrator completes the preparatory step by providing students and teachers with access to relevant electronic courses.

The training step in the DLS comprises the following components:

- academic cognitive activities if we speak about students;

- monitoring and evaluation if we speak about teachers;

- for DLS purposes, an automated monitoring of the degree of competency well-formedness.
Diagnostic materials allowing assessment of competency well-formedness serve as the input data. Students' responses to assignments are at the output. The Third-Generation Federal State Educational Standard requires that the students' training quality evaluation should include formative assessment, midterm assessment, and final state certification. Formative assessment is conducted on a regular basis in term time.

Fig. 3 presents an activity diagram of formative assessment

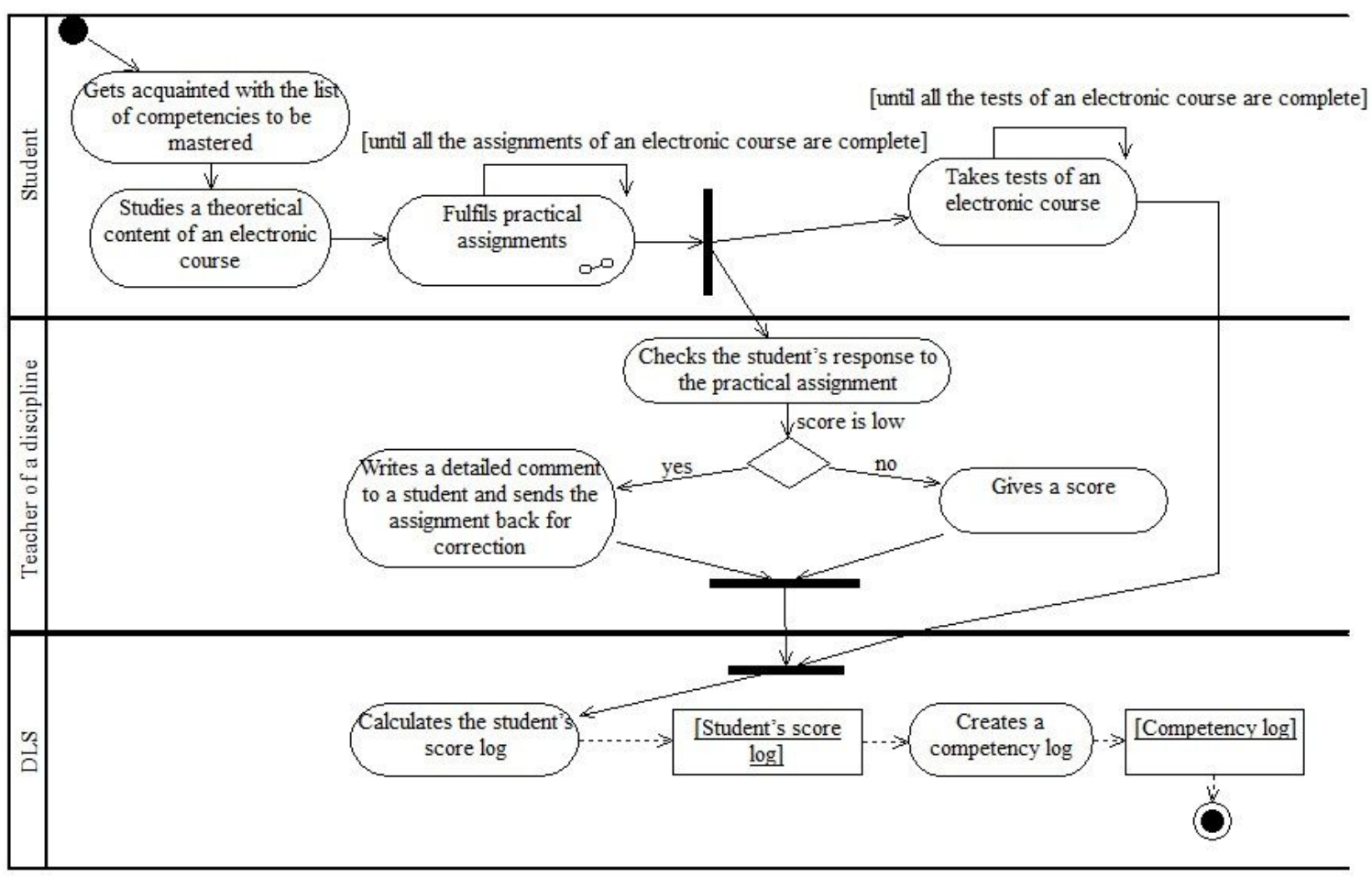

Fig. 3 - Activity diagram of formative assessment

The formative assessment makes it possible to organize a continuous monitoring of the degree of wellformedness of a certain competency. It is highly impossible to check up a competency as a whole with such assessment. However, this type of assessment enables to diagnose its separate constituents. The assessment is conducted as follows:

- a teacher checks up the results of practical assignments;

- $\quad$ students take automated tests in the system. detail.

Let's consider the above-mentioned activities in

Having completed a practical assignment of the course, a student submits it into the system. Upon receipt of a student's response, a teacher checks and scores it. In case the student fails to complete an assignment in a correct way, the teacher writes a detailed comment to the student and sends the assignment back for correction. If the teacher finds the student's work complete and correct, a score is to be assigned on a 100-point scale. The score appears in the student's score log.

If the student takes a test in an electronic course, the test is scored automatically in the DLS. And so does a test score automatically appear in the score log. At a later stage, the score-log data is used to convert the competency-log data.

The midterm assessment is conducted at the end of a semester. As a rule, it terminates study of a discipline. It is possible to assess the degree of well-formedness of certain competencies as part of this assessment. The results of diagnosis and a rating scale (assessment criteria) are input. The assessment (quantitative and qualitative) is at the output.

The analysis of the results of the midterm assessment is performed as follows:

- - the teacher checks a score log of each student. If the final discipline score is lower than $63 \%$ of 
a score maximum which a student can get in a course, the student is transferred into a group of students who have to make up missed assignments;

- - in case the training result is above $63 \%$, the student automatically gets a pass (credit) for a discipline, or takes an examination depending on the assessment mode (pass/fail examination or examination). Initially, the results of an examination period appear in the Student IS. Then, the DLS converts the degree of competency well-formedness, provided that all academic records on the disciplines are complete in the system (scores have been filled in).

Fig. 4 presents an activity diagram of the midterm assessment.

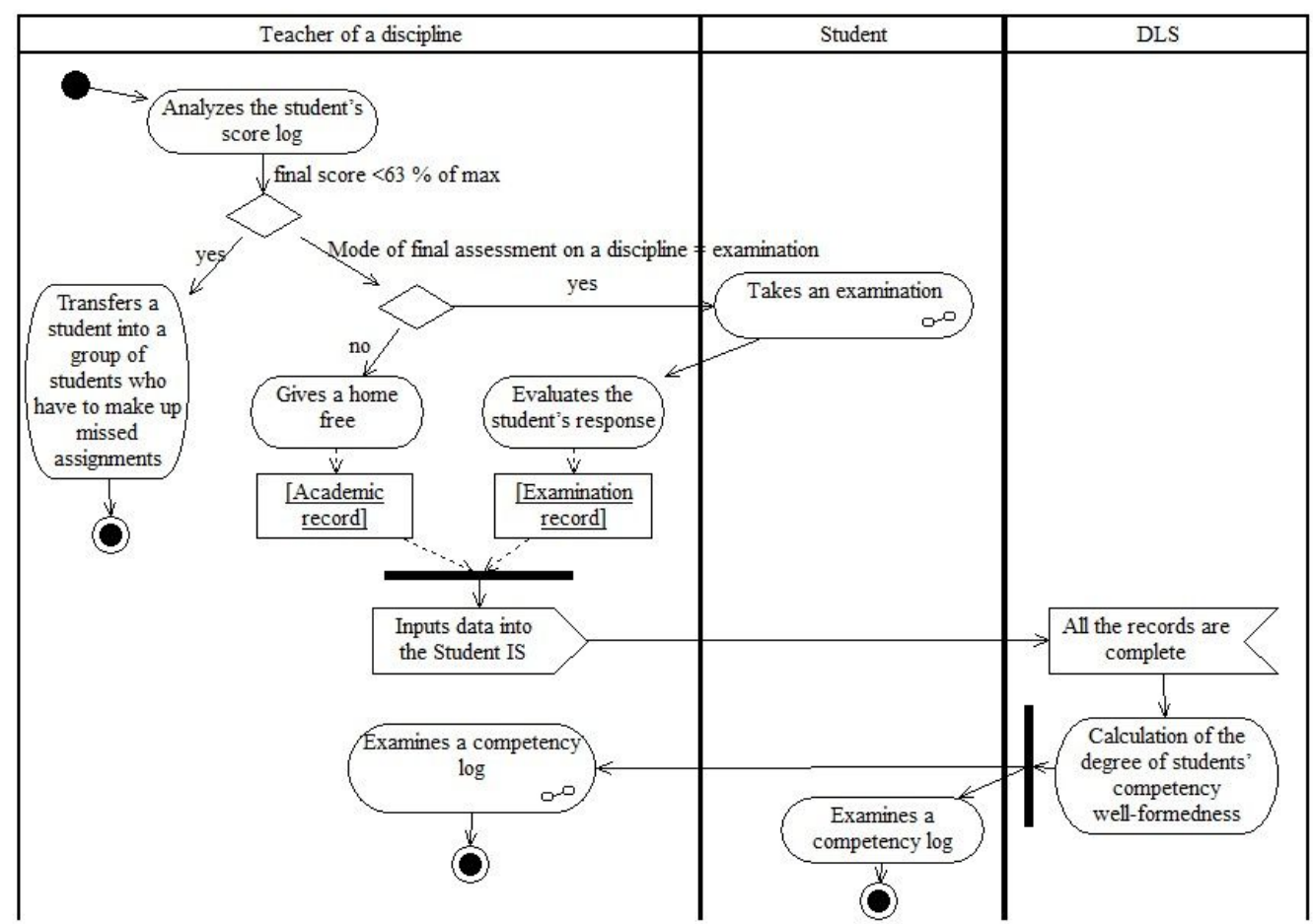

Fig. 4 - an activity diagram of the midterm assessment

The final state certification is designed to evaluate overall study results and is conducted with the participation of external experts, including employers. This type of assessment makes it possible to evaluate a combination of cross-functional and professional competencies acquired by a student. The same as in the previous cases, the results of diagnosis and a rating scale (assessment criteria) are input. The assessment (quantitative and qualitative) is at the output. The final state certification includes the state examination and defense of the graduate project for professional qualification. The curriculum developers enter the results of these examinations into the Student IS. The DLS converts the degree of well-formedness of each competency for every student, provided that all scores on the midterm assessment and the final state certification are available. Fig. 5 illustrates an activity diagram of the final state certification.

The teachers and curriculum developers analyse the study results. This step involves development of actions on filling in the "gaps" revealed. The analysis results of the specificity of the gaps revealed in the students' academic performance are at the input. Recommendations on the management of activities aiming at students' achievement of a required degree of competency well-formedness are at the output.

Given that only graduate students having more nearto-maximum competency ratings (all graduate students having equal average ratings) get a maximum competency rate, the additive convolution method is used in the objective of the competency assessment. 


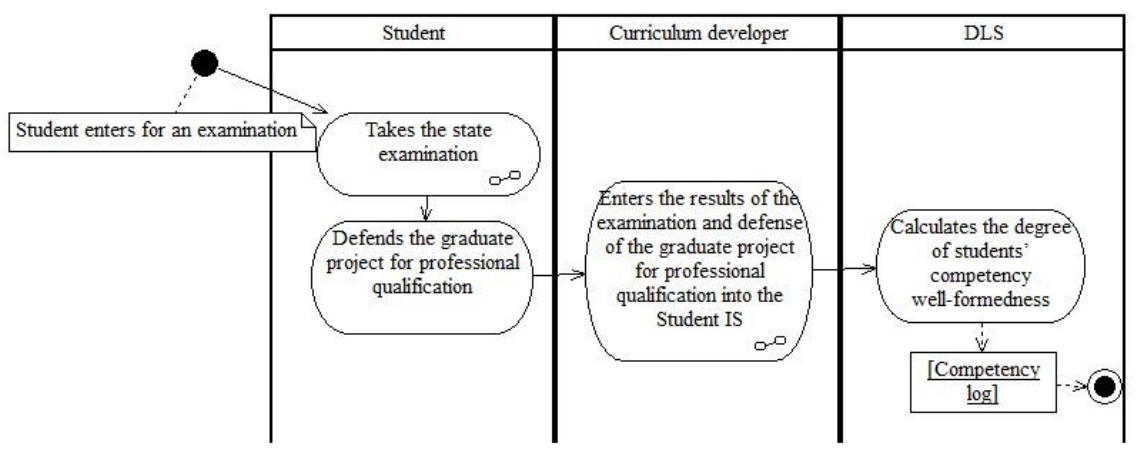

Fig. 5 - Activity diagram of the final state certification

\section{B. Mathematical model}

Scores got by the students upon completion of diagnostic materials for a certain competency and the result of a control activity (pass/fail examination or examination) have been used to develop a mathematical model of assessment of the degree of competency wellformedness.

$$
\mathrm{o}_{\mathrm{k}}=\sum_{\mathrm{i}=1}^{\mathrm{n}}\left(\sum_{\mathrm{r}=1}^{\mathrm{t}} \omega_{\mathrm{ir}}-\mathrm{b}_{\mathrm{ir}}+\theta_{\mathrm{i}}\right),
$$

where $n$ is the number of disciplines developing the competency $k$;

$t$ is the number of diagnostic materials of the discipline $i$ which test the competency $k$;

$\omega_{i r}$ is the weight of a particular diagnostic material $r$ (a test or a practical assignment) for the discipline $i$;

$\mathbf{b}_{i \mathbf{r}}$ is a score got by a student upon completion of the diagnostic material $r$ for the discipline $i$;

$\theta_{\mathrm{i}}$ is a score for an examination or a pass/fail examination on the discipline $i$ (a score for a term paper, practical training or work placement, and the final state certification may be included).

Calculation of the degree of a competency wellformedness gives a final result after the study of all the disciplines developing the competency. However, the competency development process requires monitoring and forecasting of its potential assessment at any stage of study with further correction of the competency development process $[10,11]$. In this case, a percentage of the current rate of a certain student's competency by the maximum possible rate of the competency at the current moment is calculated.

\section{Functional model}

The activity-diagram-based analysis of business processes has made it possible to distinguish the following activity types which can be automated for the University's DLS:

- import of a curriculum into the DLS;

- creation of a global group of competencies for each educational programme;

- development of electronic courses;

- creation of a local group of competencies for each electronic course;

- acquisition of information about competencies to be mastered by a student of a relevant educational programme;

- acquisition of information about disciplines that develop competencies as well as competencies that can be developed in the course of study of different disciplines;

- calculation of the degree of competency wellformedness;

- acquisition of information about the current degree of competency well-formedness of a student;

- reporting on the state of the competency development process within a separate (several) study group for a teacher/curriculum developer;

- tabular data export (additionally dedicated in the analysis).

Development of a model of the DLS structure was the next step of the research. The model features only actors and their functions that should be automated. The results of the pre-project inspection have shown that the main groups of users are:

- the DLS administrator;

- a student;

- a teacher of a course;

a curriculum developer (a group facilitator). 


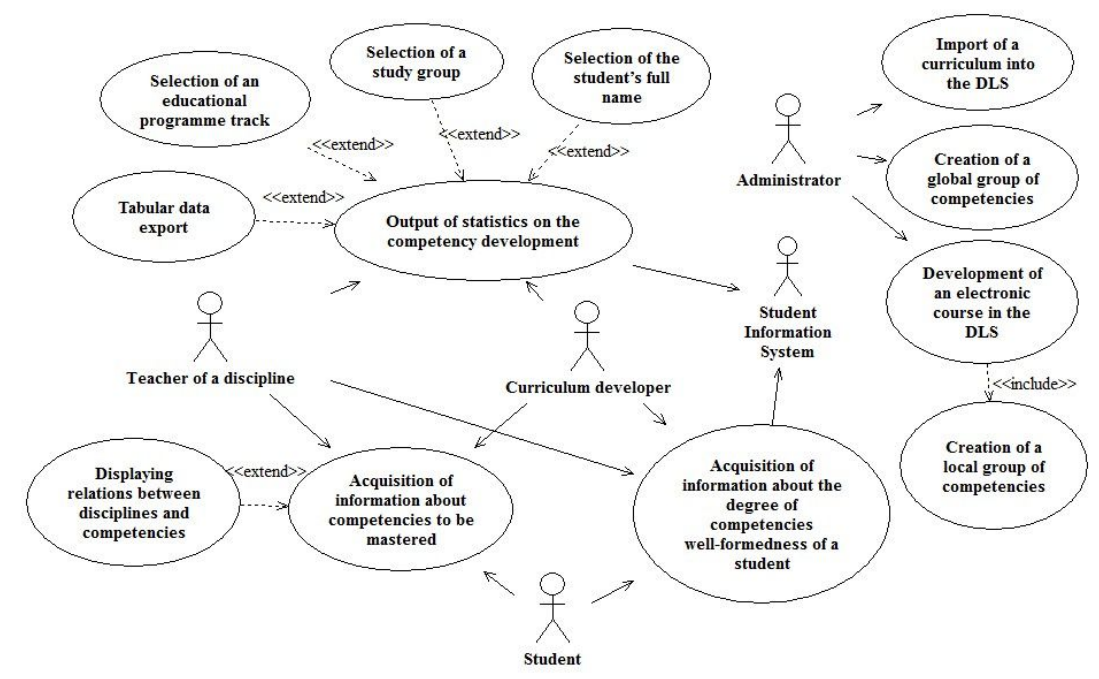

Fig. 6 - User case diagram with the users' requirements to monitoring of the degree of well-formedness of students' competencies

An external system of the Student IS is selected as a separate actor. The system provides data on the results of the midterm assessment and the final state certification. The data is required for calculation of the degree of competency well-formedness. Let's specify its main requirements for each user with a user case diagram (Fig. 6).

\section{Conceptual model}

Through the analysis of the activity and functional models of the subject domain, there have been recognized the general concepts of the subject domain that constitute a conceptual model of the process under consideration. The conceptual level is implemented by class diagrams, in which case called context diagrams, in the UML. In this case, the model demonstrates relationships between the general concepts of the subject domain.

Through the analysis of requirements, the following entities with corresponding attributes have been extracted:

- a curriculum (course code/educational programme track code, course title);

- a discipline (name, credit points, monitoring form, electronic course ID);

- a competency (code, content);
- diagnostic materials (title, weight, type, maximum score);

- a score log (attempt number, date, score);

- a student (full name, major, year, group).

Fig. 7 shows a conceptual model of the students' competencies development process.

Building the conceptual model of the process of competency development of students studying in the distant learning system terminates the modeling of the subject domain under study.

\section{CONCLUSION}

Thus, as a part of the research, the activity, functional and conceptual models of the students' competency development process have been described as in the case of the current distant learning system of the Federal State Budgetary Educational Institution of Higher Professional Education "Nosov Magnitogorsk State Technical University". The developed models of the students' competency development process provide the possibility to distinguish activity types that should be automated in the distant learning system. They also enable to depict the key entities required for monitoring of the degree of students' competency well-formedness. 


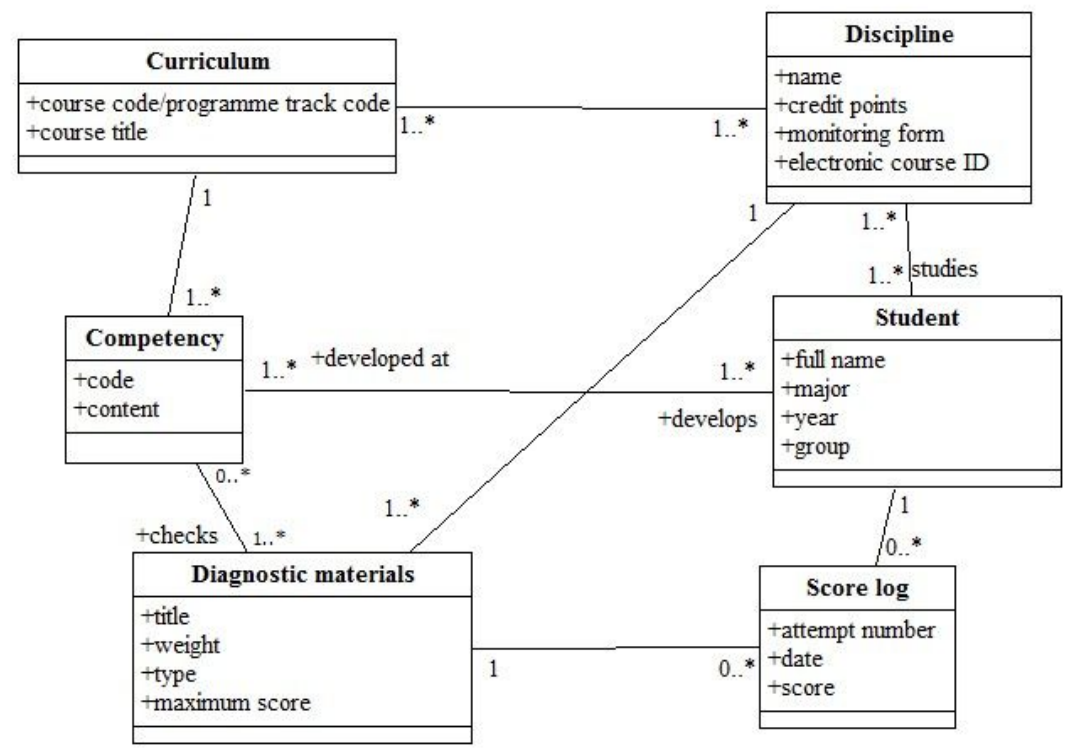

Fig. 7 - Conceptual model of the students' competency development process

The analysis of the models developed will make it possible to create a programming solution for the University's distant learning system facilitating an automated monitoring of the degree of students' competency well-formedness.

\section{References}

[1] Zimnyaya, I.A. Competencies and competence in the context of a competence-based approach in education/I.A. Zimnyaya//Scholarly notes of the national applied linguistics association. -2013. -No. 4(4). -pp. 16-31.

[2] Federal State Standards of Higher Professional Education: regulatory and legal framework of project development and implementation. - M.: Centre for Studies of quality problems of specialists training, Coordination Council of the Academic Methodological Association and the Research Methodological Council of Higher Education, 2009.

[3] Federal Targeted Programme on the development of Russian education for 2011-2015 [electronic resource] // Unified information and analysis portal of government support for innovative business development. $\quad$ M., $2014 . \quad$ URL: http://innovation.gov.ru/sites/default/files/documents/2 014/17702/3466.pdf (an access date: 4.11.2015).

[4] The Law of the Russian Federation on Education of December 29, 2012 No. 273-FZ. [Electronic resource].

URL: $\mathrm{http} / /$ минобрнауки.pф/\%D0\%B4\%D0\%BE\%D0\%B A\%D1\%83\%D0\%BC\%D0\%B5\%D0\%BD\%D1\%82\% D1\%8B/2974/\%D1\%84\%D0\%B0\%D0\%B9\%D0\%BB
$/ 1543 / 12.12 .29$ -

\%D0\%A4\%D0\%97_\%D0\%9E\%D0\%B1_\%D0\%BE\% D0\%B1\%D1\%80\%D0\%B0\%D0\%B7\%D0\%BE\%D0 \%B2\%D0\%B0\%D0\%BD\%D0\%B8\%D0\%B8_\%D0\% B2 \%D0\%A0\%D0\%BE\%D1\%81\%D1\%81\%D0\%B8 $\% \mathrm{D} 0 \% \mathrm{~B} 9 \% \mathrm{D} 1 \% 81 \% \mathrm{D} 0 \% \mathrm{BA} \% \mathrm{D} 0 \% \mathrm{BE} \% \mathrm{D} 0 \% \mathrm{~B} 9 \_\%$ D0\%A4\%D0\%B5\%D0\%B4\%D0\%B5\%D1\%80\%D0 $\% \mathrm{~B} 0 \% \mathrm{D} 1 \% 86 \% \mathrm{D} 0 \% \mathrm{~B} 8 \% \mathrm{D} 0 \% \mathrm{~B} 8$.pdf

[5] Robert, I.V. Creation and functioning of the information-educational space. Information environment of education and science electronic periodical. 2014. No. 21. pp. 78-101.

[6] Pirskaya, A.S. Graduate student's competency assessment [Text]: research and technical bulletin of Saint Petersburg State University of Information Technologies, Mechanics, and Optics / A.S. Pirskaya. 2012. No. 1 (77) - pp. 124-132.

[7] Sibikina, I.V. Models and algorithms of the graduate student's competency development and assessment [Text]: Dissert. ... of Ph.D. in Eng., 05.13.10 / I.V. Sibikina. - Astrakhan, 2012. - ASTU. - 200 p.

[8] Rumbaugh James, Jacobson Ivar, Booch Grady. UML. Computer Science Classics / S. Orlov. - 2nd edition. — SPb: Piter, 2006. — 736 p.

[9] Moodle [Electronic resource]. - URL: https://moodle.org/

[10] Tatur, Yu.G. How to enhance credibility of measuring and assessment of educational results. Higher education in Russia. 2010. No. 5. pp. 22-31.

[11] Shikhova, O.F., Shikhov Yu.A. Qualimetric approach to the diagnostics of university graduate students' competencies. Education and science. 2013. No. 4 (103). pp. 40-57. 